\title{
Cranial venous sinus dominance: what to expect? Analysis of 100 cerebral angiographies
} Dominância dos seios venosos cranianos: o que esperar? Análise de 100 angiografias cerebrais

Matheus Augusto Pinto Kitamura', Leonardo Ferraz Costa', Danilo Otávio de Araújo Silva², Laécio Leitão Batista ${ }^{3}$, Maurus Marques de Almeida Holanda ${ }^{4}$, Marcelo Moraes Valença ${ }^{1}$

\begin{abstract}
We report an analysis of the cranial venous sinuses circulation, emphasizing morphological and angiographic characteristics. Methods: Data of 100 cerebral angiographies were retrospectively analyzed ( $p=0.05$ ). Results: Mean age was 56.3 years, $62 \%$ female and $38 \%$ male. Measurements and dominance are shown in the Tables. There was no association between age or gender and dominance. Right parasagittal division of the superior sagittal sinus was associated with right dominance of the transverse sinus, sigmoid sinus and internal jugular vein; and left parasagittal division of the superior sagittal sinus was associated with left dominance of the transverse sinus, sigmoid sinus and internal jugular vein. Conclusion: A dominance pattern of cranial venous sinuses was found. Age and gender did not influence this pattern. Angiographic findings, such as division of the superior sagittal sinus, were associated with a pattern of cranial venous dominance. We hope this article can add information and assist in preoperative venous analysis for neurosurgeons and neuroradiologists.
\end{abstract}

Keywords: cranial sinuses; cerebral angiography; anatomy.

\section{RESUMO}

Relatamos uma análise da circulação dos seios venoso cranianos, enfatizando características morfológicas e angiográficas. Métodos: Dados de 100 angiografias cerebrais foram retrospectivamente analisados ( $p=0,05$ ). Resultados: Média de idade 56,3 anos, 62\% feminino e 38\% masculino. Medições e dominância expostos em tabelas. Sem associação entre idade ou sexo e dominância. Divisão parassagittal direita do Seio Sagital Superior (SSS) foi associada com dominância direita do Seio Transverso (ST), Seio Sigmóide (SS) e Veia Jugular Interna (VJI), e divisão parassagittal esquerda do SSS foi associada com dominância esquerda do ST, SS e VJI. Conclusão: Um padrão de dominância dos seios venosos do crânio foi encontrado. Idade e sexo não influenciaram esse padrão. Achados angiográficos, como divisão do SSS, foram associados com o padrão de dominância venoso cerebral. Esperamos que este artigo acrescente informações e auxilie na análise venosa pré-operatória para neurocirurgiões e neuroradiologistas.

Palavras-chave: seios cranianos; angiografia cerebral; anatomia.

The cranial venous sinuses are channels lined by endothelial layers located between the periosteal (outer) and meningeal (internal) dura mater ${ }^{1}$. They collect blood from the superficial and deep cerebral veins, meninges and calvarium, and form the main drainage route of the cranial cavity ${ }^{2}$.

The understanding of the cranial venous sinus anatomy is fundamental in neurosurgery and radiology, especially in surgical planning and treatment of neurological diseases, and to avoid complications s, $3,5,6,7,8,9$. The cerebral venous drainage dominance analysis should be considered before operations on patients for a large variety of neurosurgical diseases, especially if possible coagulation of venous structures is needed ${ }^{5}$. Analysis of cranial venous dominance is of great importance in many neurosurgeries, as well in neck surgeries ${ }^{5}$. Venous sinus analysis by angiography is usually recommended as the best preoperative evaluation for diseases involving the major sinuses ${ }^{10}$. We found a lack of publications in our region on this matter.

In this article, we report on the angiographic analysis of cranial venous sinus circulation, emphasizing morphological and angiographic characteristics and possible associations, aiming to contribute to current neurosurgical and radiological knowledge.

1 Universidade Federal de Pernambuco, Departamento de Neuropsiquiatria, Recife PB, Brasil;

${ }^{2}$ Cleveland Clinic, Neurological Institute, Department of Neurosurgery, Cleveland, $\mathrm{OH}, \mathrm{USA}$;

${ }^{3}$ Universidade Federal de Pernambuco, Departamento de Radiologia, Recife PE, Brasil;

«Universidade Federal da Paraíba, Departamento de Neurologia, João Pessoa PB, Brasil.

Correspondence: Matheus Augusto Pinto Kitamura;Avenida Consul Joseph Noujaim,146 / ap.603;51110-150 Recife PE, Brasil;E-mail:matheus_kitamura@yahoo.com.br Conflict of interest: There is no conflict of interest to declare.

Received 02 September 2016; Received in final form 30 December 2016; Accepted 24 January 2017. 


\section{METHODS}

A total of 104 cerebral angiographies were retrospectively obtained from two reference centers. All examinations were performed by the same radiology team, with a similar pattern, and analyzed by the chief radiologist of the team. The research project was approved by the Ethics Committee of the Federal University of Pernambuco. Consent letters were obtained for the collection of the data.

The study was of $2 \mathrm{D}$ angiograms, adapting to a reality of a developing center in our region. After four angiograms were excluded due to venous sinus thrombosis, a total of 100 cerebral angiograms were analyzed. Data were analyzed descriptively (average) and by association tests (contingency table and Fisher Exact Test). The level of significance was $5 \%(p=0.05)$. The variables were organized in epidemiological and angiographic groups. The epidemiological variables were age, gender and reason for the examination. The angiographic variables were measurement and measurement ratio of the transverse sinus (TS), sigmoid sinus (SS) and internal jugular vein (IJV); jugular bulb height; division point of the superior sagittal sinus (SSS); presence of occipital sinus (OS); visualization of the mastoid emissary vein; and presence of the suboccipital venous plexus.

Data were organized in spreadsheets using Microsoft Excel (v. 2011, Microsoft Corp.) and were statistically analyzed using Graphpad Prism (v.6, Graphpad Software, Inc.). Angiographies were analyzed using an Osirix Dicom Viewer (v. 5.8, Pixmeo Sarl Corp.). Measurements were initially acquired in pixels and subsequently converted into millimeters.

The midline was defined by a line perpendicular to the mean distance between the medial border of the orbital rims, and assisted by calcification of faux when visible. The TS measurement was acquired between the ninth and tenth portion of the distance between the edges of one side to the other. The SS measurement was acquired at the average distance of the length of the sinus. The IJV measurement was acquired at the first possible moment of defining the limits of its walls, just below the jugular bulb, at the frontal incidence of angiography. The analysis is exemplified in Figure 1.

The measurement ratio right/left of the sinuses (or IJV) were stratified according to dominance. A venous sinus was classified as dominant when the measurement ratio was more than 1.5 (dominant right) or less than 0.67 (dominant left) (sinus measurement was more than $50 \%$ than the contralateral side). A venous sinus was classified as symmetrical when the measurement ratio was equal or between 1.5 and 0.67 (sinuses measuring between the limit of 50\%).

The jugular bulb height was analyzed using a line at the top limit of each jugular bulb to the contralateral side, parallel to the line between the medial borders of the orbital rims.
It was classified as being the same height when the lines were coincident or within a limit of $5 \mathrm{~mm}$, and as high/redundant when the lines were spaced apart over a limit of $5 \mathrm{~mm}$. This is exemplified in Figure 2.

\section{RESULTS}

\section{Epidemiological data}

The mean age of the patients was 56.3 years (22 to 89 years). The gender distribution was $62 \%$ female and $38 \%$ male.

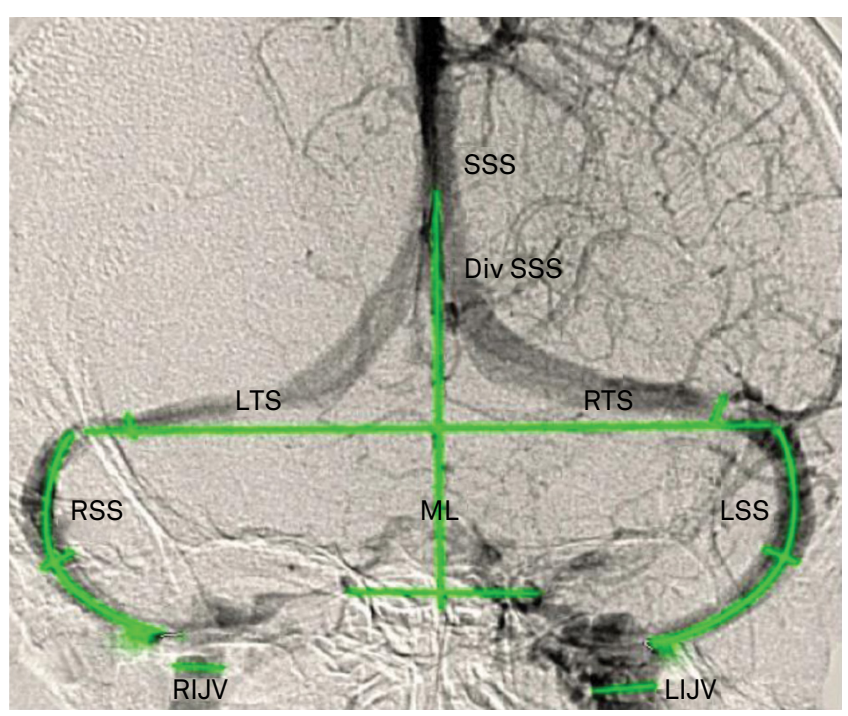

SSS: superior sagittal sinus; DivSSS: division point of superior sagittal sinus; RTS: right transverse sinus; LTS: left transverse sinus; RSS: right sigmoid sinus; LSS: left sigmoid sinus; RIJV: right internal jugular vein; LIJV: left internal jugular vein; ML: Midline.

Figure 1. Methodology for analysis of images: venous aspect of cerebral angiography, frontal view.

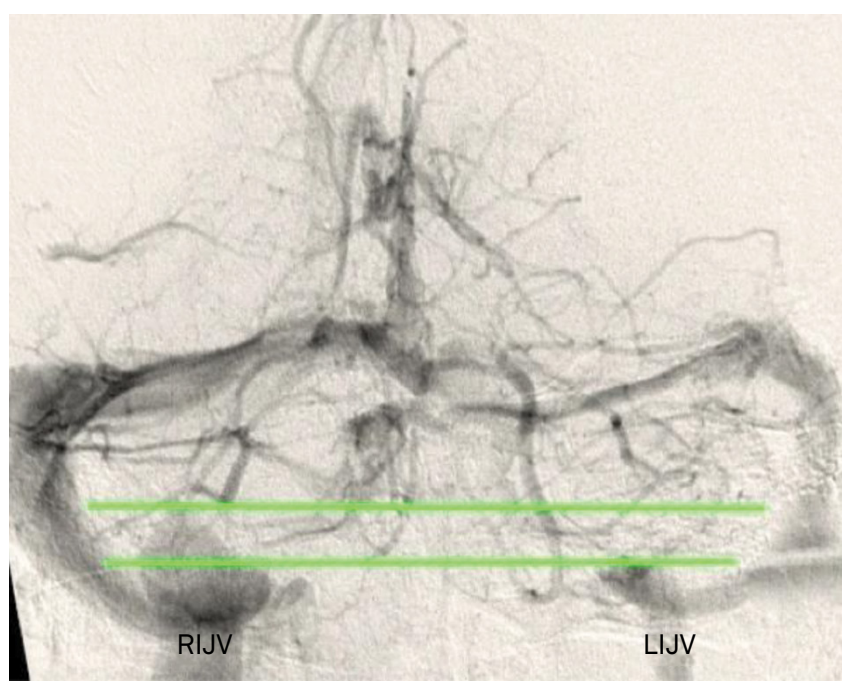

RIJV: right internal jugular vein; LIJV: left internal jugular vein.

Figure 2. Methodology for jugular bulb analysis: venous aspect of cerebral angiography, frontal view. High bulb on the right side (patient 79). 
The most common reason for angiographic examination was suspicion of a cerebral aneurysm (38\%).

\section{Dominance of cranial venous sinuses}

The overall average measurements, including gender distribution, and the dominance pattern of the TS, SS and IJV are reported in Tables 1 and 2. Patterns of dominance are exemplified in Figures 3 and 4.

The division of the SSS was parasagittal right in 34\%, parasagittal left in $12 \%$, and sagittal in $54 \%$ of patients.

There was no statistically significant association between age or gender and venous sinus dominance. The data of dominance according to gender are shown in Table 3.

The presence of right parasagittal division of the SSS was associated with right dominance of the TS, SS and IJV, with an odds ratio of 33.8 ( $p<0.0001), 9.4$ ( $p<0.0001)$ and 15.2 ( $p<0.0001)$, respectively. The presence of left parasagittal division of the SSS was associated with left dominance of the TS, SS and IJV, with an odds ratio of $27.3(\mathrm{p}<0.0001)$, $8.7(p=0.0023)$ and $5.8(p=0.0255)$, respectively. The dominance data according to the division of SSS are shown in Table 4. An example of the division correlation between the SSS and dominance is shown in Figure 4.

\section{Additional findings}

For the upper limit of the jugular bulb, our study found the same level in $70 \%$ of patients: $19 \%$ high bulb on the right side and $11 \%$ high bulb on the left side. A high bulb is exemplified in Figure 2.

The occipital marginal sinus was present in $18 \%$ of patients. The right mastoid vein was present in $29 \%$ and left mastoid vein in $22 \%$. The suboccipital venous plexus was present in $58 \%$.

Table 1. Measurements vs distribution according to gender.

\begin{tabular}{lccc} 
Measurement vs. Distribution & $\begin{array}{c}\text { General } \\
(\mathrm{mm})\end{array}$ & $\begin{array}{c}\text { Male } \\
(\mathrm{mm})\end{array}$ & $\begin{array}{c}\text { Female } \\
(\mathrm{mm})\end{array}$ \\
\hline Right TS & 6.4 & 6.8 & 6.1 \\
Left TS & 5.4 & 5.1 & 5.6 \\
Right SS & 6.5 & 6.8 & 6.3 \\
Left SS & 5.3 & 5.2 & 5.3 \\
Right IJV & 9.1 & 9.0 & 9.3 \\
Left IJV & 7.4 & 6.8 & 7.8 \\
\hline
\end{tabular}

TS: transverse sinus; SS: sigmoid sinus; IJV: internal jugular vein.

Table 2. Dominance analysis.

\begin{tabular}{lccc}
\hline Sinus/vein vs. Dominance & $\begin{array}{c}\text { Right } \\
(\%)\end{array}$ & $\begin{array}{c}\text { Left } \\
(\%)\end{array}$ & $\begin{array}{c}\text { Symmetry } \\
(\%)\end{array}$ \\
\hline TS & 36 & 14 & 50 \\
SS & 35 & 15 & 50 \\
IJV & 33 & 11 & 56 \\
\hline TS: transverse sinus:SS: sigmoid sinus:IJV· internal jugular vein
\end{tabular}

\section{DISCUSSION}

The SSS originates just behind the paranasal frontal sinuses, near the crista galli and progressively increases in size to continue later in a shallow depression of the mid-sagittal inner table of the skull, collecting numerous parasagittal veins ${ }^{11-13}$. It drains into the transverse sinus in the internal occipital protuberance through a complex plexiform venous confluence, called the torcula Herophili (confluence of sinuses) ${ }^{12}$.

Variations of the torcula have been described according to its anatomic composition ${ }^{14}$. The SSS can end directly in the

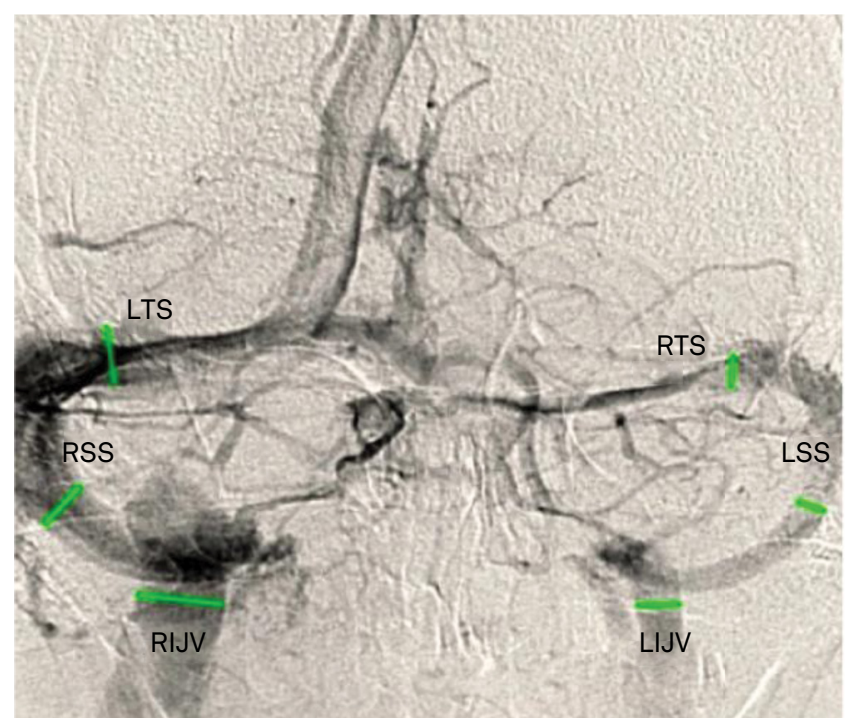

RTS: right transverse sinus; LTS: left transverse sinus; RSS: right sigmoid sinus; LSS: left sigmoid sinus; RIJV: right internal jugular vein; LIJV: left internal jugular vein.

Figure 3. Patient 78, right dominance of the transverse sinus, sigmoid sinus and internal jugular vein.

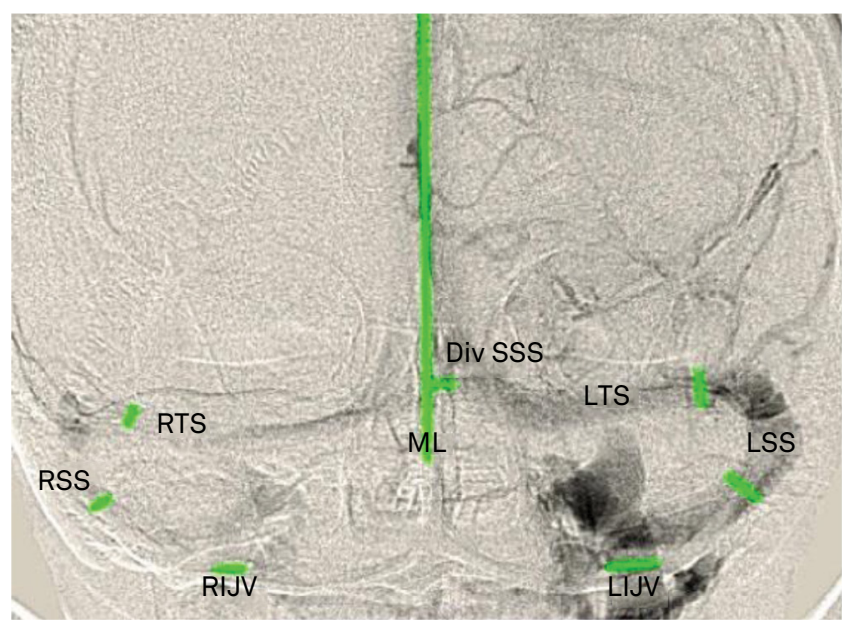

RTS: right transverse sinus; LTS: left transverse sinus; RSS: right sigmoid sinus; LSS: left sigmoid sinus; RIJV: right internal jugular vein; LIJV: left internal jugular vein; DivSSS: Division point of superior sagittal sinus; ML: midline.

Figure 4. Patient 40, left dominance of transverse sinus, sigmoid sinus and internal jugular vein, with parasagittal left division of superior sagittal sinus. 
Table 3. Gender vs. dominance according to gender distribution.

\begin{tabular}{lcccc|}
\hline Variable & $\begin{array}{c}\text { Right } \\
(\%)\end{array}$ & $\begin{array}{c}\text { Left } \\
(\%)\end{array}$ & $\begin{array}{c}\text { Symmetry } \\
(\%)\end{array}$ & $\begin{array}{c}\text { Total } \\
(\%)\end{array}$ \\
\hline Gender vs. TS Dominance & & & & \\
\hline Male & 19 & 4 & 15 & 38 \\
\hline Female & 17 & 10 & 35 & 62 \\
\hline Total & 36 & 14 & 50 & 100 \\
\hline Gender vs. SS Dominance & & & & \\
\hline Male & 19 & 4 & 15 & 38 \\
\hline Female & 16 & 11 & 35 & 62 \\
\hline Total & 35 & 15 & 50 & 100 \\
\hline Gender vs. IJV Dominance & & & & \\
\hline Male & 15 & 4 & 19 & 38 \\
\hline Female & 18 & 7 & 37 & 62 \\
\hline Total & 33 & 11 & 56 & 100 \\
\hline TS: transverse sinus; SS: sigmoid sinus; IJV: internal jugular vein. &
\end{tabular}

Table 4. Division of SSS vs. dominance according to the division point of the superior sagittal sinus.

\begin{tabular}{|c|c|c|c|c|}
\hline Variable & $\begin{array}{l}\text { Right } \\
(\%)\end{array}$ & $\begin{array}{l}\text { Left } \\
(\%)\end{array}$ & $\begin{array}{c}\text { Symmetrical } \\
(\%)\end{array}$ & $\begin{array}{c}\text { Total } \\
(\%)\end{array}$ \\
\hline \multicolumn{5}{|c|}{ Division of SSS vs. TS Dominance } \\
\hline Parasagittal right & 28 & 0 & 6 & 34 \\
\hline Parasagittal left & 0 & 8 & 4 & 12 \\
\hline Sagittal & 8 & 6 & 40 & 54 \\
\hline Total & 36 & 14 & 50 & 100 \\
\hline \multicolumn{5}{|c|}{ Division of SSS vs. SS Dominance } \\
\hline Parasagittal right & 23 & 0 & 11 & 34 \\
\hline Parasagittal left & 0 & 6 & 6 & 12 \\
\hline Sagittal & 12 & 9 & 33 & 54 \\
\hline Total & 35 & 15 & 50 & 100 \\
\hline
\end{tabular}

Division of SSS vs. IJV Dominance

\begin{tabular}{lcccc} 
Parasagittal right & 24 & 1 & 9 & 34 \\
Parasagittal left & 0 & 4 & 8 & 12 \\
Sagittal & 9 & 6 & 39 & 54 \\
Total & 33 & 11 & 56 & 100 \\
\hline
\end{tabular}

TS: transverse sinus; SS: sigmoid sinus; IJV: internal jugular vein SSS: superior sagittal sinus.

transverse sinus. In this situation, the transverse sinus of the opposite side, generally, is hypoplasic or missing ${ }^{11}$. The SSS can be continued as a right transverse sinus and the straight sinus can become the left transverse sinus, associated with hypoplasia of the torcula Herophili2. The presence of a septum may have implications in the analysis of the torcula flow ${ }^{15}$. There may also be a compartment inside a venous sinus, which can be important in the treatment of a dural fistula by endovascular procedure ${ }^{16}$.

The SSS often deviates slightly to the right as it runs inferiorly along the occipital bone, which ends up becoming the right transverse sinus. In about $20 \%$ of normal patients, the SSS deviates more than $1 \mathrm{~cm}$ from the midline ${ }^{11}$. An angiographic study by Shima et al. showed a percentage of $40.3 \%$, in which the division point of the SSS was to the right in comparison to its anterior portion, $35.4 \%$ situated in the midline, $19.4 \%$ left, $2.7 \%$ indeterminate and $2.3 \%$ absent $^{17}$.

In the present study, the division of the SSS was sagittal in most cases (54\%), followed by parasagittal right (34\%) and parasagittal left (12\%).

The OS begins on the posterior margin of the foramen magnum and passes superiorly toward the torcula. It communicates with the internal jugular vein, with the vertebral venous plexus and the clival venous plexus through multiple small channels ${ }^{18}$. In about $2 \%$ of patients, the OS behaves as a major drainage channel to the straight sinus or SSS ${ }^{19,20}$.

In our study, the OS was present in $18 \%$ of patients.

The TS is contained within the connections of the leaves of the tentorium with the calvarium. ${ }^{13}$ It starts at the internal occipital protuberance and bow, anterior and lateral to the petrous temporal bone. At the posterior edge of the petrous temporal bone, the TS receives the superior petrosal sinus and then turns downward and medially, leaving the tentorium and becoming the sigmoid sinus ${ }^{2,21}$.

Some anatomic studies ${ }^{4,6,8,22}$ have shown right dominance of the TS as the most common pattern (45-75\%). Symmetrical (19-41\%) and left dominance (14-29\%) were less frequent. Another anatomic study by Park et al. showed right dominance in $35.5 \%$ and symmetry in $58.1 \%{ }^{15}$ A study based on CT scans by Friedmann et al. ${ }^{7}$ showed that the right-sided venous dominance was most common (70-80\%), and the venous system was larger in men than women. A study based on magnetic resonance venography by Manara et al., ${ }^{23}$ showed that the mean caliber of the right TS was significantly greater than the contralateral sinus $(6.5 \mathrm{~mm}$ +/-1.84 vs. $5.1 \mathrm{~mm}+/-1.72)$. Right and left dominance was observed in $61 \%$ and $17 \%$ of cases, respectively.

In a radiological study using angiography by Modic et al., ${ }^{9}$ right dominance was found in 56\%, symmetry in $26 \%$ and left dominance in $18 \%$. Another angiographic study, by Shima et al. ${ }^{17}$, analyzed 253 angiographies and found right dominance in $51.3 \%$, symmetry in $33.5 \%$ and left dominance in $9.5 \%$. An angiographic retrospective study with 189 patients, by Durgun et al., 5 showed $41.3 \%$ with right dominance drainage, $37.6 \%$ with equal drainage and $18.5 \%$ with left dominance drainage.

Our study showed a greater measurement of the right TS $(6.4 \mathrm{~mm})$ in comparison to the left TS $(5.4 \mathrm{~mm})$. The TS had right dominance in $36 \%$ of patients; left in $14 \%$ and $50 \%$ were symmetrical. We found no association between the measurements according to gender (Table 1).

The SS is the anterior and inferior continuation of the TS. After a gentle S-shaped curve, behind the petrous portion of the temporal bone, the SS reaches the jugular foramen and ends at the jugular bulb. The lateral sinus is formed by the junction of the TS and SS on each side ${ }^{2,21}$. 
Regarding the dominance of the SS, an autopsy study by Gotto $^{24}$ found right dominance in $70.2 \%$, equal in $18.3 \%$ and left in $11.5 \%$. An angiographic study by Shima et al. ${ }^{17}$ showed right dominance in $29.3 \%$, symmetrical in $49.0 \%$, and left in $14.1 \%$.

In our study, the SS had right dominance in $35 \%$ of cases, left dominance in $15 \%$ and symmetry in $50 \%$.

The IJV begins at the jugular fossa, as a continuation of the SS. Its initial portion has a small expansion called the jugular bulb. It ends by uniting with the respective subclavian vein to form the brachiocephalic vein ${ }^{2}$.

Regarding the dominance of the IJV, the autopsy study by Gotto $^{24}$ showed right dominance in $67.4 \%$, equal in $20.5 \%$ and left in $12.1 \%$. Shima et al's angiographic study ${ }^{17}$ showed right dominance in $14.2 \%$, symmetry in $64.2 \%$ and left dominance in $4.2 \%$.

The present study showed a symmetry of $56 \%$ between the IJVs, a right dominance in $33 \%$ and left dominance in $11 \%$.

During the literature review, including our own results, it was observed that there is a pattern in some of the literature with approximate results, but there is some variety where numbers are reported. We believe these differences may be due to epidemiological aspects (population, gender, age) and different examinations (CT, MR, autopsy, angiography). We believe aspects such as absence (autopsy) or presence (angiographic) of venous flow, 3D (autopsy) or 2D (angiographic) measurement acquisition, visualization of the vein wall (autopsy) or contrast view of vein lumen (angiographic), among others, may account for these differences.

The jugular bulb is the initial portion of the IJV in the jugular fossa. Occasionally, the upper portion is located higher than usual (high/redundant bulb), usually unilaterally. Because of its close relationship with the pneumatized petrous bone, this can be the cause for pulsatile tinnitus. ${ }^{2}$ Identification of a high jugular bulb has great value when planning surgeries through the temporal bone and some authors have tried to correlate this with other anatomic findings ${ }^{25}$. The study by Friedmann et al. ${ }^{7}$ showed that jugular bulbs were not detected in patients younger than two years, became enlarged in adulthood, and remained stable in the elderly.

As for the upper limit of the jugular bulb, our study found approximately the same level in $70 \%$ of cases (respecting our limit definition). In the remaining patients (30\%), 19 patients demonstrated a higher jugular bulb on the right, and in 11 patients it was on the left.

Shima et al. ${ }^{17}$ analyzed the pattern for the division of the SSS and showed concordance between the dominance of TS, SS and IJV.

Our study showed that the presence of a parasagittal right division of the SSS was associated with dominance of the right TS, SS and IJV, and the presence of left parasagittal division of the SSS was associated with left dominance of the ST, SS and IJV, with statistical significance.

In conclusion, the dominance pattern of cranial venous sinuses found in this study, is consistent with some of the literature.

Epidemiological data, such as age and gender did not influence the pattern of dominance of the cranial venous sinuses.

The division of the SSS has significant association with the dominance of the TS, SS and IJV.

\section{References}

1. Parent A. Cerebral veins and venous sinuses. In: Parent A. Carpenter's Human neuroanatamy, 9th ed. Media: Williams and Wilkins; Baltimore. 1996. p. 120-8.

2. Osborn AG. Angiografia cerebral diagnóstica. 2nd ed. Revinter, 2002. Chapter 10: As veias extracranianas e os seios venosos durais; Philadellphia p. 195-216.

3. Bisaria KK. Anatomic variations of venous sinuses in the region of the torcular Herophili. J Neurosurg. 1985;62(1):90-5. https://doi.org/10.3171/jns.1985.62.1.0090

4. Browning $\mathrm{H}$. The confluence of dural venous sinuses. Am J Anat. 1953;93(3):307-29. https://doi.org/10.1002/aja.1000930302

5. Durgun B, Ilglt ET, Cizmeli MO, Atasever A. Evaluation by angiography of the lateral dominance of the drainage of the dural venous sinuses. Surg Radiol Anat. 1993;15(2):125-30. https://doi.org/10.1007/BF01628311

6. Frenckner P. Value of roentgenography in estimating degree to which lateral sinus and jugular vein allow emptying of venous blood from skull including few remarks on sinography. Acta Otolaryngol (Stockh). 1940;28:7-35.

7. Friedmann DR, Eubig J, McGill M, Babb JS, Pramanik BK, Lalwani AK. Development of the jugular bulb: a radiologic study. Otol Neurotol. 2011;32(8):1389-95. https://doi.org/10.1097/MAO.0b013e31822e5b8d
8. Ishizaka H. [Anatomical study of th2 torcula Herophili]. Neurol Med Chir (Tokyo). 1985;25(11):873-80. Japanese. https://doi.org/10.2176/nmc.25.873

9. Modic MT, Weinstein MA, Starnes DL, Kinney SE, Duchesneau PM. Intravenous digital subtraction angiography of the intracranial veins and dural sinuses. Radiolology. 1983;146(2):383-9. https://doi.org/10.1148/radiology.146.2.6336847

10. Mantovani A, Di Maio S, Ferreira MJ, Sekhar LN. Management of meningiomas invading the major dural venous sinuses: operative technique, results, and potential benefit for higher grade tumors. World Neurosurg. 2014;82(3-4):455-67. https://doi.org/10.1016/j.wneu.2013.06.024

11. Curé JK, Van Tassel P, Smith MT. Normal and variant anatomy of the dural venous sinuses. Semin Ultrasound CT MR. 1994;15(6):499-519. https://doi.org/10.1016/S0887-2171(05)80019-8

12. Oka K, Rhoton A, Tomonaga M. Microsurgical anatomy of superficial cortical veins, superior sagittal sinus, and venous lacunae. In: Hakuba A. Surgery of the intracranial venous system. Basek: Springer; 1995. p. 43-9.

13. Rhoton ALJr. The cerebral veins. Neurosurgery. 2002;51(4 Suppl):S159-205.

14. Gökçe E, Pınarbașılı T, Acu B, Fırat MM, Erkorkmaz Ü. Torcula Herophili classifications and evaluation of dural venous sinus using digital subtraction angiography and magnetic resonance venographies. Surg Radiol Anat. 2014;36(6):527-36. https://doi.org/10.1007/s00276-013-1223-0 
15. Park HK, Bae HG, Choi SK, Chang JC, Cho SJ, Byun BJ et al. Morphological study of sinus flow in the confluence of sinuses. Clin Anat. 2008;21(4):294-300. https://doi.org/10.1002/ca.20620

16. Piske RL, Campos CM, Chaves JB, Abicalaf R, Dabus G, Batista LL et al. Dural sinus compartment in dural arteriovenous shunts: a new angioarchitectural feature allowing superselective transvenous dural sinus occlusion treatment. AJNR Am J Neuroradiol. 2005;26(7):1715-22.

17. Shima T, Okita S, Okada Y, Nishida M, Yamane K, Hatayama T. Anatomical dominance of venous sinuses and jugular vein examined by intravenous digital subtraction angiography. In: Hakuba A. Surgery of the intracranial venous system. Basel: Springer; 1995. p. 58-62.

18. Braun JP, Tournade A. Venous drainage in the craniocervical region. Neuroradiology. 1977;13(3):155-8. https://doi.org/10.1007/BF00626278

19. Kaplan HA, Browder J, Krieger AJ. Venous channels within the intracranial dural partitions. Radiology. 1975;115(3):641-5. https://doi.org/10.1148/15.3.641
20. Lang J. Clinical anatomy of the posterior cranial fossa and its foramina. New York: Thieme; 1991.

21. Alaywan M, Sindou M. Surgical anatomy of the lateral sinus for approaches in the sigmoid region. In: Hakuba A. Surgery of the intracranial venous system. Basel: Springer; 1995. p. 63-72.

22. Zouaoui A, Hidden G. Cerebral venous sinuses: anatomical variants or thrombosis? Acta Anat (Basel). 1988;133(4):318-24. https://doi.org/10.1159/000146661

23. Manara R, Mardari R, Ermani M, Severino MS, Santelli L, Carollo C. Transverse dural sinuses: incidence of anatomical variants and flow artefacts with $2 \mathrm{D}$ time-of-flight MR venography at 1 Tesla. Radiol Med (Torino). 2010;115(2):326-38. https://doi.org/10.1007/s11547-010-0480-9

24. Goto N. Anatomy of the cerebral vessels. Tokyo: Nihon Acsel Springer; 1986.

25. Inal M, Muluk NB, Dağ E, Arıkan OK, Kara SA. The pitfalls and important distances in temporal bone HRCT of the subjects with high jugular bulbs: preliminary report. Adv Clin Exp Med. 2015;24(2):315-24. https://doi.org/10.17219/acem/40472 